„Analiza finansowa ekonomicznej kondycji na przykładzie polskich instytucji”

M. Kępa, Wroclaw University of Economics

A. Lisek, Wroclaw University of Economics

K. Madej, Wroclaw University of Economics

M. Sieczka, Wroclaw University of Economics

Streszczenie: Celem pracy jest analiza sytuacji finansowej trzech podmiotów: organizacji non profit, instytucji finansowej oraz spółki akcyjnej. Praca zawiera obliczenia wskaźników, które posłużyły do skonstruowania miary $\varphi$ Zietlow'a. Dane do obliczeń zostały zaczerpnięte ze sprawozdań finansowych poszczególnych jednostek. Wskaźnik $\varphi$ ma na celu zobrazować sytuację finansową danej jednostki: jej wypłacalność, płynność finansową oraz zdolności adaptacyjne do zmieniających się warunków. Obliczenia te mają być źródłem cennych informacji dla osób zarządzających danym podmiotem. Dzięki nim możliwe jest zanalizowanie, w którym obszarze jednostka prosperuje lepiej, a w którym gorzej i wprowadzenie potrzebnych zmian. Miara $\varphi$ jest podsumowaniem wszystkich wskaźników i daje ogólny obraz sytuacji finansowej danego podmiotu.

Słowa kluczowe: wypłacalność, płynność finansowa, wskaźnik $\varphi$, analiza finansowa

„Financial analysis of economic health - Polish entities case”

Summary: The aim of this report is to analyze the financial situation of three entities: nonprofit organizations, financial institutions and joint- stock company. The work includes the calculation of indicators that were used to construct a measure of $\varphi$ Zietlow'a. Data for the 
calculations were taken from the financial statements of individual units. $\Phi$ indicator is to illustrate the financial position of the entity: its solvency, liquidity and ability to adapt to changing conditions. These calculations are source of valuable information for the management of the entity. They make it possible to analyze, in which area the unit thrives better and the worse and introduce the necessary changes. Measure $\varphi$ is a summary of all the indicators and gives an overall picture of the financial situation of a company.

Keywords: solvency, financial liquidity, $\varphi$ indicator, financial analysis

JEL: A10, G32, L31, L33

Recenzent 1: M. Wiącek

Treść recenzji 1: http://dx.doi.org/10.6084/m9.figshare.875432

Recenzent 2: D. Kasprzak

Treść recenzji 2: http://dx.doi.org/10.6084/m9.figshare.875478 
Wstęp

Każda jednostka gospodarcza, aby osiągnąć swój cel, musi być odpowiednio zarządzana, a zarządzanie to proces, na który składa się m.in. podejmowanie decyzji ${ }^{1}$. Osoby zarządzające podejmują decyzje na podstawie analizy danych. Analiza ekonomiczna jest swego rodzaju narzędziem do obiektywnej oceny efektywności działania danego podmiotu gospodarczego $^{2}$. Jej celem jest głównie właściwe i rzetelne rozpoznanie sytuacji finansowej organizacji ${ }^{3}$. Przedstawiona w pracy analiza dotyczy lat 2008, 2009 i 2010. Zachowanie takich samych jednostek czasu jest konieczne, aby można było porównać badane zjawiska oraz określić tendencje rozwojowe ${ }^{4}$. Analizowane podmioty mają różne formy prawne. Jedną $\mathrm{z}$ analizowanych jednostek jest organizacja non profit (Z), która prowadzi działalność niezarobkową ${ }^{5}$ Celem takiej organizacji jest poprawa życia członków, organizacji, wspólnot lub całego społeczeństwa ${ }^{6}$. Kolejną jednostką jest bank (X), czyli osoba prawna, utworzona na podstawie ustawy, posiadająca zezwolenie do wykonywania czynności bankowych ${ }^{7}$. Ostatnim podmiotem jest spółka akcyjna (Y), czyli organizacja prywatnoprawna, powołana przez założycieli w dowolnym, zgodnym z prawem celu ${ }^{8}$.

Treść pracy

W poniższej pracy omówiono 15 wskaźników, które składają się na Financial Health Index. Ukazują one, jak na przestrzeni lat 2008-2010 kształtowały się płynność, czyli

\footnotetext{
${ }^{1}$ D. Jemielniak, D. Latusek, Zarzadzanie: teoria i praktyka od podstaw. Ćwiczenia, Wyd. Wyższa Szkoła Przedsiębiorczości i Zarządzania im. Leona Koźmińskiego, Warszawa 2005, s. 11.

${ }^{2}$ Z. Leszczyński, A. Skowronek-Mielczarek, Analiza działalności i rozwoju przedsiębiorstwa, Polskie Wydawnictwo Ekonomiczne, Warszawa 2008, s. 17.

${ }^{3}$ R. Borowiecki, A. Jaki (red.), Wspótczesne problemy analizy ekonomicznej, Wyd. Katedra Ekonomiki i Organizacji Przedsiębiorstw Uniwersytetu Ekonomicznego w Krakowie, Kraków 2010, s. 26.

${ }^{4}$ Z. Leszczyńki, A. Skowronek-Mielczarek, Analiza ekonomiczno-finansowa firmy, Wyd. Difin, Warszawa 2001, s. 20.

${ }^{5}$ J. Fudaliński, Perspektywy rozwoju zarzadzania społecznego w sektorze organizacji non profit w Polsce, Wyd. Difin, Warszawa 2013, s. 21.

${ }^{6}$ M.J. Epstein, F. Warren McFarlan, Joining a Nonprofit Board. What you need to know, Wyd. Jossey-Bass A Wiley Imprint, San Francisco 2011, s. 1.

${ }^{7}$ Z. Ofiarski, Prawo bankowe, Wyd. Wolters Kluwer Polska, Warszawa 2011, s. 17.

${ }^{8}$ J. Okolski (red.), Prawo handlowe, Wyd. Wolters Kluwer Polska, Warszawa 2008, s. 270.
} 
możliwość przedsiębiorstwa do regulowania krótkoterminowych zobowiązań ${ }^{9}$, elastyczność finansowa, która pozwala przedsiębiorstwu sprawnie funkcjonować oraz wpływa na jego konkurencyjność i efektywność ${ }^{10}$, a także wypłacalność, która odnosi się do możliwości pokrywania zobowiązań długoterminowych ${ }^{11}$. Poniższa praca prezentuje analizę podmiotów gospodarczych w sposób zaproponowany przez prof. Zietlow'a w jego publikacji ${ }^{12}$.

Miara $\varphi$ składa się z 4 kategorii. Pierwsza, czyli General Category jest obliczana jako ważona wartość trzech wskaźników: Natural Logarithm of Age, Natural Logarithm of Size i Asset Instability Index. Wskaźniki te służą do zobrazowania elastyczności finansowej jednostki.

Wzór 1

GENERAL SUBSCORE $=(1,25 \times$ Age $)+(0,33 \times$ Size $)+(-0,00001 \times$ Asset Intensity Index $)^{13}$

W instytucji finansowej X zmiany w latach 2008-2010 kształtowały się następująco: 10,92; 10,94; 11,01. Można zauważyć tendencję wzrostową, która oznacza bardzo dobrą sytuację finansową firmy, wynikającą ze wzrostu jej stabilności. Wartość wskaźnika oscyluje wokół wartości 10, co jest najbardziej pożądaną wartością możliwą do osiągnięcia. W przedsiębiorstwie Y General Subscore wynosił w poszczególnych latach: 9,92; 10,01; 10,05, co wskazuje na dobrą sytuację finansową owego przedsiębiorstwa. General Subscore w organizacji Z także przybrał tendencję wzrostową, przyjmując w kolejnych latach następujące

\footnotetext{
${ }^{9}$ T. Korol, Nowe podejście do analizy wskaźnikowej w przedsiębiorstwie, Wyd. Wolters Kluwer Polska, Warszawa 2013, s. 24.

${ }^{10}$ J. M. Lichtarski, M. Moroz, G. Osbert-Pociecha, Elastyczność przedsiębiorstwa jako konfiguracja elastyczności cząstkowych, Gospodarka Narodowa, Nr 4, 2008, s. 59.

${ }^{11}$ J. Grant, P. Munter, T. R. Robinson, Financial statement analysis: a global perspective, Pearson Education International, New Jersey 2004, s. 239.

${ }^{12}$ J. Zietlow, A Financial Health Index for Achieving Nonprofit Financial Sustainability, Dostęp SSRN: http://ssrn.com/abstract=2049022, ostatni dostęp 02.12.2013.

${ }_{13}$ J. Zietlow, A Financial Health Index for Achieving Nonprofit Financial Sustainability, Dostęp SSRN: http://ssrn.com/abstract=2049022, ostatni dostęp 02.12.2013.
} 
wartości 8,$67 ; 8,84 ; 8,9$, co podobnie jak w pozostałych omawianych jednostkach wskazuje na dobrą sytuację finansową tego podmiotu.

Druga omawiana kategoria to Immediate-Term Category, na którą składają się odpowiednio ważone wskaźniki: Cash Reserve Sufficiency Ratio, będący wskaźnikiem płynności określa możliwość pokrywania wydatków pieniężnych gotówką, Modified Cash Ratio określający wypłacalność jednostek, Target Liquidity Lambda, który uwzględniając wieloletnie przepływy pieniężne ${ }^{14}$, określa ile razy przedsiębiorstwo będzie w stanie pokryć nieprzewidziane wydatki ze swoich rezerw gotówkowych ${ }^{15}$ oraz Current Liquidity Index obliczany na podstawie wzoru przedstawionego przez Zietlow'a i Maness'a ${ }^{16}$.

\section{Wzór 2}

IMMEDIATE-TERM SUBSCORE $=(1,25 \mathrm{x}$ Cash Reserve Sufficiency Ratio $)+(12,5 \mathrm{x}$ Modified Cash Ratio $)+(0,85 \times$ Target Liquidity Lambda $)+(0,5 \times \text { Current Liquidity Index })^{17}$

Immediate-Term Subscore w instytucji finansowej X kształtował się następująco: 3,$39 ; 10,89 ; 14,47$. Widoczny jest stały wzrost wskaźnika, co wskazuje na wzrost kondycji finansowej firmy i znaczny rozwój. W przedsiębiorstwie Y zanotowano następujące wartości Immediate-Term Subscore: 1,$86 ; 3,40 ; 3,33$. W drugim roku zauważalny jest niemal dwukrotny wzrost wskaźnika, po czym w ostatnim roku wartość ta nieznacznie spada. Mimo to, w ciągu trzech lat wskaźnik wzrósł o 79\%, co oznacza rozwój przedsiębiorstwa i polepszenie jego kondycji finansowej. Immediate-Term Subscore w organizacji Z w latach 2008-2010 przyjmował kolejno wartości: 0,58; 7,62; 6,74. W drugim roku zanotowano ponad

\footnotetext{
${ }^{14}$ Z. Gołaś, A. Witczyk, Pojęcie i metody oceny plynności finansowej przedsiębiorstwa, Journal of Agribusiness and Rural Development, Nr 1(15), 2010, s. 92.

${ }^{15}$ D. Wędzki, Analiza wskaźnikowa sprawozdania finansowego, Wyd. Wolters Kluwer Polska, Kraków 2006, s. 323.

${ }^{16}$ T. S. Maness, J. Zietlow, Short-term Financial Management, Wyd. Thomson South-Western, Mason 2005, s. 40.

${ }^{17}$ J. Zietlow, A Financial Health Index for Achieving Nonprofit Financial Sustainability, Dostęp SSRN: http://ssrn.com/abstract=2049022, ostatni dostęp 02.12.2013.
} 
13-krotny wzrost wskaźnika, po czym w roku 2010 wartość ta spada, ale nadal utrzymuje się na bezpiecznym poziomie.

Kolejną kategorią jest Short-Term Category. Jest ona obliczana jako wartość ważona wskaźników: Operating Cash Flow Ratio, który określa zdolność pokrycia zobowiązań z dodatnich przepływów pieniężnych z działalności operacyjnej, Asset Ratio określający udział aktywów obrotowych w ogólnej liczbie aktywów oraz Administrative Expense Ratio, którego spadek mógłby przyczynić się do wzrostu efektywności organizacji. Do tej kategorii prof. Zietlow zaliczył wskaźniki różnych typów, gdyż OCF Ratio jest wskaźnikiem płynności, Asset Ratio określa wypłacalność a Administrative Expense Ratio pomaga przeanalizować zdolność jednostki do dopasowania się do zmieniających się warunków rynkowych.

\section{Wzór 3}

SHORT-TERM SUBSCORE $=(0,75$ x Operating Cash Flow Ratio $)+(6,6 \times$ Asset Ratio $)+$ $(8,33 x \text { Administrative Expense Ratio })^{18}$

W instytucji finansowej X Short-Term Subscore w latach 2008-2010 kształtował się odpowiednio na poziomie: 0,$49 ; 0,46 ; 0,16$. Widoczny jest stały spadek wartości wskaźnika, co oznacza spadek efektywności finansowej firmy. 6,$14 ; 6,20 ; 6,71$ to wartości, jakie omawiany wskaźnik przyjął w przedsiębiorstwie Y. Stały stopniowy wzrost zwiększa efektywność finansową jednostki. Short-Term Subscore w organizacji Z przyjmował wartości 13,54; 146,43; 3,86. Ostateczny znaczny spadek wskaźnika w roku 2010 wskazuje na duże zmniejszenie efektywności finansowej podmiotu.

Ostatnią omawianą kategorią jest Medium-Term Category, na którą składają się odpowiednio ważone składniki: wskaźnik płynności Net Surplus, którego wahania wiążą się z

\footnotetext{
${ }^{18}$ J. Zietlow, A Financial Health Index for Achieving Nonprofit Financial Sustainability, Dostęp SSRN: http://ssrn.com/abstract=2049022, ostatni dostęp 02.12.2013.
} 
niestabilnością wartości aktywów, wskaźnik wypłacalności Financial Debt Ratio, który określa jaką część finansowania działalności przedsiębiorstwo pokrywa zadłużeniem oraz wskaźniki finansowej elastyczności Contribution Ratio, Self-Financing Ratio określający poziom samofinansowania organizacji i Fundraising Cost Ratio.

Wzór 4

MEDIUM-TERM SUBSCORE $=(0,00001 \times$ Net Surplus $)+(-2 \times$ Contribution Ratio $)+(2 \times$ Self-Financing Ratio $)+(-2$ x Financial Debt Ratio $)+(-2 \text { x Fundraising Cost Ratio })^{19}$

W instytucji finansowej X Medium-Term Subscore wynosił w poszczególnych latach: 20,39; 67,25; 7,62. W drugim badanym roku wskaźnik ten wzrósł ponad 3-krotnie, jednak w ostatnim roku nastąpił spadek, który świadczy o tym, że pogorszyła się kondycja finansowa. W przedsiębiorstwie Y wskaźnik ten w latach 2008-2010 kształtował się na poziomie -12,03; -10,17; -7,04. Ujemne wartości wskaźnika wskazują na znaczny spadek tego składnika w ogólnej kondycji finansowej. Sytuacja jednak ulega poprawie, co obrazuje zwiększająca się wartość wskaźnika. Medium-Term Subscore dla organizacji Z przybrał następujące wartości: -22,44; 42,64; 21,64. Pozytywny wzrost w roku 2009 został zastąipiony spadkiem w roku następnym. Mimo to wskaźnik nadal utrzymuje się na wysokim poziomie.

Powyższe wskaźniki składają się na główny wskaźnik kondycji finansowej jednostki Financial Health Index $(\varphi)$.

\section{Wzór 5}

FINANCIAL HEALTH INDEX $(\varphi)=(0,10 \times$ General Subscore $)+(0,40 \times$ Immediate-Term Subscore $)+(0,30 x$ Short-Term Subscore $)+(0,20 \times \text { Medium-Term Subscore })^{20}$

\footnotetext{
${ }^{19}$ J. Zietlow, A Financial Health Index for Achieving Nonprofit Financial Sustainability, Dostęp SSRN: http://ssrn.com/abstract=2049022, ostatni dostęp 02.12.2013.
} 
Instytucja finansowa X na przełomie 2008/2009 roku osiągnęło wzrost wskaźnika $\varphi$ z 6,67 do 19,03, co oznacza wzrost kondycji finansowej podmiotu. Sytuacja uległa zmianie w 2010 roku, kiedy nastąpił spadek wartości $\varphi$. Może to oznaczać tendencję firmy do niestabilności kondycji finansowej. W przedsiębiorstwie Y wskaźnik $\varphi$ w latach 2008-2010 kształtował się następująco: 1,$17 ; 2,19 ; 2,94$. Tendencja wzrostowa $(251 \%$ wzrost na przestrzeni trzech lat) pozwala stwierdzić, że omawiana organizacja jest w bardzo dobrej sytuacji, a jej kondycja finansowa wzrasta. $\mathrm{W}$ organizacji $\mathrm{Z} \varphi$ przybrał następujące wartości: 0,84; 56,39; 9,09. Wzrost w roku 2009 wskazywał na znaczne polepszenie kondycji finansowej jednostki. Znaczący spadek wskaźnika w kolejnym roku oznacza spadek i niestabilność kondycji finansowej organizacji Z.

Poniższy wykres (Wykres 1) przedstawia wartości wskaźnika $\varphi$ dla wszystkich badanych organizacji na przestrzeni lat 2008-2010. Jak widać, tylko przedsiębiorstwo prywatne $\mathrm{w}$ formie spólki akcyjnej charakteryzuje się niewielkim, aczkolwiek stałym wzrostem wskaźnika $\varphi$. Oznacza to, że jego kondycja finansowa jest doba, odznacza się stabilnością i zdolnościami adaptacyjnym do zmiennych warunków zewnętrznych. Natomiast pozostałe dwie jednostki odznaczają się gwałtownymi wzrostami i spadkami wskaźnika $\varphi$, co oznacza że ich kondycja finansowa jest niestabilna.

\footnotetext{
${ }^{20}$ J. Zietlow, A Financial Health Index for Achieving Nonprofit Financial Sustainability, Dostęp SSRN: http://ssrn.com/abstract=2049022, ostatni dostęp 02.12.2013.
} 
Wykres 1

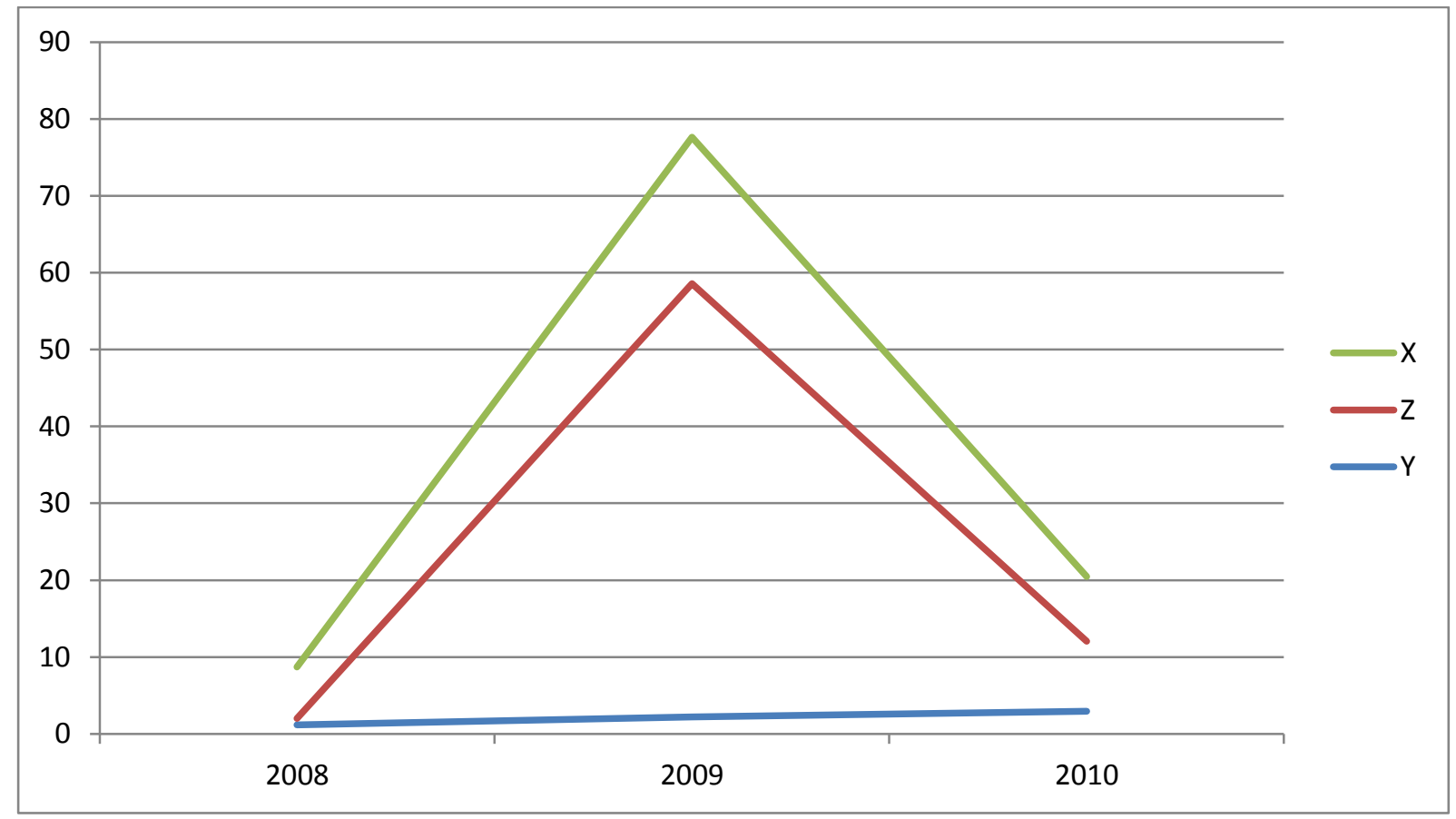

Źródło: Opracowanie własne na podstawie: J. Zietlow, A Financial Health Index for Achieving Nonprofit Financial Sustainability (2012). Dostęp SSRN: http://ssrn.com/abstract=2049022, ostatni dostęp: 29 listopada 2013.

\section{Zakończenie}

Wskaźnik Financial Health Index skonstruowany przez prof. Zietlowa stanowi nowatorskie podejście do oceny sytuacji finansowej przedsiębiorstwa. Biorąc pod uwagę, w odpowiednich proporcjach, 15 wskaźników składających się na 4 kategorie doszedł on do ogólnego wskaźnika kondycji finansowej przedsiębiorstwa. W swojej pracy Zietlow przedstawił obliczenia, na podstawie których ocenił kondycję finansową organizacji nonprofit (dokładniej Armii Zbawienia). Jednak nic nie stoi na przeszkodzie, aby jego metodę zastosować również do zbadania sytuacji finansowej w instytucji finansowych oraz innych przedsiębiorstwach, których celem jest maksymalizacja zysku.

Niniejsza praca ukazuje analizę kondycji finansowej trzech podmiotów działających na rynku w różnych formach. Są to organizacja non-profit, instytucja finansowa oraz przedsiębiorstwo prywatne $\mathrm{w}$ formie spółki akcyjnej. Obliczenia wzorowane na podejściu 
prof. Zietlow'a pozwoliły ocenić kondycję finansową tych podmiotów na przestrzeni lat 2008-2010.

\section{Załączniki:}

1. Tabela 1: Analiza $\Phi$ dla instytucji finansowej $X$

2. Tabela 2: Analiza $\Phi$ dla spółki akcyjnej Y

3. Tabela 3: Analiza $\Phi$ dla organizacji non profit $Z$

4. Bibliografia 
Tabela 1: Analiza $\Phi$ dla instytucji finansowej X

\begin{tabular}{|c|c|c|c|c|}
\hline Wskaźnik & 2008 & 2009 & 2010 & Interpretacja \\
\hline 1. Age & 4,49 & 4,50 & 4,51 & $\begin{array}{l}\text { Stopniowy wzrost wskaźnika oznacza, iż } \\
\text { organizacja charakteryzuje się większą } \\
\text { stabilnością i elastycznością finansową. }\end{array}$ \\
\hline 2.Size & 16,28 & 16,30 & 16,45 & $\begin{array}{l}\text { Wzrost wskaźnika oznacza, większą } \\
\text { stabilność i elastyczność } \\
\text { związaną ze wzrostem dochodu. }\end{array}$ \\
\hline $\begin{array}{l}\text { 3.Asset } \\
\text { Instability } \\
\text { Index }\end{array}$ & 6494,51 & 6152,37 & 5663,27 & $\begin{array}{l}\text { Aktywa wykazują tendencję spadkową, ich } \\
\text { niestabilność powoduje trudności w } \\
\text { zarządzaniu. }\end{array}$ \\
\hline $\begin{array}{l}\text { General } \\
\text { Subscore }\end{array}$ & 10,92 & 10,94 & 11,01 & $\begin{array}{l}\text { Zauważalna tendencja wzrostowa oznacza } \\
\text { bardzo dobrą sytuację finansową firmy. }\end{array}$ \\
\hline $\begin{array}{l}\text { 4.Cash } \\
\text { Reserve } \\
\text { Sufficienty } \\
\text { Ratio }\end{array}$ & 2,36 & 3,10 & 2,25 & $\begin{array}{l}\text { Zdolność pokrycia zobowiązań z dodatnich } \\
\text { przepływów pieniężnych z działalności } \\
\text { operacyjnej utrzymuje się na podobnym } \\
\text { poziomie. }\end{array}$ \\
\hline $\begin{array}{l}\text { 5.Modified } \\
\text { Cash Ratio }\end{array}$ & $-0,01$ & 0,004 & $-0,002$ & $\begin{array}{l}\text { W drugim roku nastąpił znaczny } \text { wzrost } \\
\text { wskaźnika, co oznacza } \\
\text { wypłacalności, ale następnie spadł do } \\
\text { niskiego poziomu. }\end{array}$ \\
\hline 6.Lambda & 0,47 & 8,02 & 13,62 & $\begin{array}{l}\text { Stały wzrost wskaźnika } \text { zmniejsza } \\
\text { prawdopodobieństwo braku gotówki w } \\
\text { przyszłości. }\end{array}$ \\
\hline $\begin{array}{l}\text { 7.Current } \\
\text { liquidity } \\
\text { index }\end{array}$ & 0,28 & 0,30 & 0,22 & $\begin{array}{l}\text { Sytuacja korzystna dla firmy, ponieważ } \\
\text { zobowiązania wymagalne } \\
\text { zabezpieczone, czyli będą uregulowane. }\end{array}$ \\
\hline $\begin{array}{l}\text { Immediate- } \\
\text { Term } \\
\text { Subscore }\end{array}$ & 3,39 & 10,89 & 14,47 & $\begin{array}{l}\text { Wskaźnik stale wzrasta, co wskazuje na } \\
\text { wzrost kondycji finansowej firmy i znaczny } \\
\text { rozwój. }\end{array}$ \\
\hline $\begin{array}{l}\text { 8.OCF } \\
\text { Ratio }\end{array}$ & 0,20 & 0,19 & 0,01 & $\begin{array}{l}\text { Zdolność do pokrycia zobowiązań } \mathrm{z} \\
\text { dodatnich przepływów pieniężnych } \mathrm{z} \\
\text { działalności operacyjnej maleje } \mathrm{z} \text { każdym } \\
\text { rokiem. }\end{array}$ \\
\hline $\begin{array}{l}\text { 9.Asset } \\
\text { Ratio }\end{array}$ & 0,011 & 0,014 & 0,009 & $\begin{array}{l}\text { Przedsiębiorstwo doświadcza wzrostu i } \\
\text { spadku udziału aktywów obrotowych w } \\
\text { ogólnej liczbie aktywów. }\end{array}$ \\
\hline $\begin{array}{l}\text { 10.Adminis } \\
\text { trative } \\
\text { Expense } \\
\text { Ratio }\end{array}$ & 0,032 & 0,026 & 0,011 & $\begin{array}{l}\text { Organizacja jest bardziej efektywna, gdyż } \\
\text { stosunek kosztów administracyjnych spada. } \\
\text { Oznacza to mniejszą zdolność do pokrycia } \\
\text { takich wydatków w przypadku kryzysu. }\end{array}$ \\
\hline $\begin{array}{l}\text { Short-Term } \\
\text { Subscore }\end{array}$ & 0,49 & 0,46 & 0,16 & $\begin{array}{l}\text { Spadek wskaźnika oznacza spadek } \\
\text { efektywności finansowej firmy. }\end{array}$ \\
\hline $\begin{array}{l}\text { 11.Net } \\
\text { Surplus }\end{array}$ & 1972785 & 6484070 & 923698 & $\begin{array}{l}\text { Niestabilność wskaźnika wiąże się } \mathrm{z} \\
\text { niestabilnością wartości aktywów. }\end{array}$ \\
\hline
\end{tabular}




\begin{tabular}{|c|c|c|c|c|}
\hline $\begin{array}{l}\text { 12.Contribu } \\
\text { tion Ratio }\end{array}$ & 1,19 & 1,71 & 1,53 & $\begin{array}{l}\text { Spadek wartości wskaźnika w } 2010 \text { oznacza } \\
\text { większą elastyczność finansową i mniejsze } \\
\text { ryzyko. }\end{array}$ \\
\hline $\begin{array}{l}\text { 13.Self- } \\
\text { Financing } \\
\text { Ratio }\end{array}$ & 2,30 & 3,59 & 1,39 & $\begin{array}{l}\text { Organizacja chcąc } \\
\text { samofinansowania w aktywa trwałe będzie } \\
\text { dążyć do wartości 1 lub więcej, co oznacza, } \\
\text { że wyższe wartości można wykorzystać na } \\
\text { kapitał obrotowy. }\end{array}$ \\
\hline $\begin{array}{l}\text { 14.Financia } \\
1 \text { Debt } \\
\text { Ratio }\end{array}$ & 0,47 & 0,46 & 0,46 & $\begin{array}{l}\text { Spadek wskaźnika wiąże się ze spadkiem } \\
\text { zobowiązań. }\end{array}$ \\
\hline $\begin{array}{l}\text { 15.Fundrais } \\
\text { ing Cost } \\
\text { Ratio }\end{array}$ & 0,31 & 0,21 & 0,20 & $\begin{array}{l}\text { Zauważalny niski procent pozyskiwania } \\
\text { funduszy związany jest z tym, że omawiana } \\
\text { organizacja nie jest organizacją non profit }\end{array}$ \\
\hline $\begin{array}{l}\text { Medium- } \\
\text { Term } \\
\text { Subscore }\end{array}$ & 20,39 & 67,25 & 7,62 & $\begin{array}{l}\text { Wzrost wskaźnika wskazuje na znaczny } \\
\text { wzrost tego składnika w ogólnej kondycji } \\
\text { finansowej. Niestety w ostatnim roku } \\
\text { nastąpił spadek, który świadczy o tym, że } \\
\text { kondycja finansowa się pogorszyła. }\end{array}$ \\
\hline$\Phi$ & 6,67 & 19,03 & 8,46 & $\begin{array}{l}\text { Organizacja finansowa na przełomie } 2008 \mathrm{i} \\
2009 \text { roku osiągnęła wzrost wskaźnika } \varphi \text {. } \\
\text { Oznacza to wzrost kondycji finansowej } \\
\text { danej organizacji. Niestety ta sytuacja nie } \\
\text { utrzymała się długo, gdyż w } 2010 \text { nastąpił } \\
\text { spadek } \varphi \text {. Może to oznaczać tendencję } \\
\text { firmy do niestabilności kondycji finansowej. }\end{array}$ \\
\hline
\end{tabular}

Źródło: Opracowanie własne na podstawie: J. Zietlow, A Financial Health Index for Achieving Nonprofit Financial Sustainability (2012). Dostęp SSRN: http://ssrn.com/abstract=2049022, ostatni dostęp: 29 listopada 2013.

Tabela 2: Analiza $\Phi$ dla spółki akcyjnej Y

\begin{tabular}{|l|l|l|l|l|}
\hline Wskaźnik & 2008 & 2009 & 2010 & Interpretacja \\
\hline 1.Age & 4,70 & 4,71 & 4,72 & $\begin{array}{l}\text { Wskaźnik stopniowo wzrasta, to oznacza, że } \\
\text { przedsiębiorstwo charakteryzuje się większą } \\
\text { stabilnością i elastycznością finansową. }\end{array}$ \\
\hline 2. Size & 12,46 & 12,67 & 12,85 & $\begin{array}{l}\text { Wzrost wskaźnika oznacza wękequa } \\
\text { stabilność i elastyczność finansową } \\
\text { przedsiębiorstwa. }\end{array}$ \\
\hline $\begin{array}{l}\text { 3. Asset } \\
\text { Instability } \\
\text { Index }\end{array}$ & 6680,36 & 6018,62 & 9303,77 & $\begin{array}{l}\text { Wzrost aktywów na przestrzeni lat jest } \\
\text { niestabilny, co oznacza trudności w } \\
\text { zarządzaniu. }\end{array}$ \\
\hline $\begin{array}{l}\text { General } \\
\text { Subscore }\end{array}$ & 9,92 & 10,01 & 10,05 & $\begin{array}{l}\text { Zauważalna tendencja wzrostowa oznacza } \\
\text { bardzo dobrą sytuację finansową firmy. }\end{array}$ \\
\hline $\begin{array}{l}\text { 4. Cash } \\
\text { Reserve } \\
\text { Sufficiency }\end{array}$ & 0,76 & 0,85 & 0,80 & $\begin{array}{l}\text { Zdolność do pokrycia zobowiązań z } \\
\text { dodatnich przepływów pieniężnych z z } \\
\text { działalności operacyjnej wzrosła w drugim }\end{array}$ \\
\hline
\end{tabular}




\begin{tabular}{|c|c|c|c|c|}
\hline Ratio & & & & $\begin{array}{l}\text { roku, po czym spadła do pierwotnej } \\
\text { wartości. }\end{array}$ \\
\hline $\begin{array}{l}\text { 5. Modified } \\
\text { Cash Ratio }\end{array}$ & $-0,002$ & 0,038 & $-0,016$ & $\begin{array}{lll}\text { W drugim roku nastąpił znaczny } & \text { wzrost } \\
\text { wskaźnika, co oznacza } & \text { wzrost } \\
\text { wypłacalności, który nie utrzymał się w } \\
\text { kolejnym roku. }\end{array}$ \\
\hline $\begin{array}{l}6 . \quad \text { Target } \\
\text { Liquidity } \\
\text { Lambda }\end{array}$ & 0,67 & 1,79 & 2,49 & $\begin{array}{l}\text { Znaczny wzrost wskaźnika w kolejnych } \\
\text { latach zmniejsza prawdopodobieństwo } \\
\text { braku gotówki w przyszłości. }\end{array}$ \\
\hline $\begin{array}{l}\text { 7. Current } \\
\text { Liquidity } \\
\text { Index }\end{array}$ & 0,72 & 0,69 & 0,64 & $\begin{array}{l}\text { Wartość wskaźnika stale maleje, co oznacza } \\
\text { spadek wypłacalności przedsiębiorstwa. }\end{array}$ \\
\hline $\begin{array}{l}\text { Immediate- } \\
\text { Trem } \\
\text { Subscore }\end{array}$ & 1,86 & 3,40 & 3,33 & $\begin{array}{l}\text { Wartość wskaźnika wzrosła w drugim roku, } \\
\text { następnie zmalała w ostatnim roku. }\end{array}$ \\
\hline $\begin{array}{l}\text { 8. OCF } \\
\text { Ratio }\end{array}$ & 0,70 & 0,68 & 0,64 & $\begin{array}{l}\text { Zdolność do pokrycia zobowiązań } \\
\text { dodatnich przepływów pieniężnych } \\
\text { działalności operacyjnej maleje z każdym } \\
\text { rokiem. }\end{array}$ \\
\hline $\begin{array}{l}\text { 9.Asset } \\
\text { Ratio }\end{array}$ & 0,39 & 0,46 & 0,49 & $\begin{array}{llll}\text { Przedsiębiorstwo } & \text { doświadcza } & \text { wzrostu } \\
\text { udziału aktywów } & \text { obrotowych } & \text { w } & \text { ogólnej } \\
\text { liczbie aktywów. } & & & \end{array}$ \\
\hline $\begin{array}{l}10 . \\
\text { Administrat } \\
\text { ive Expense } \\
\text { Ratio }\end{array}$ & 0,37 & 0,32 & 0,36 & $\begin{array}{l}\text { Im niższy wskaźnik tym organizacja } \\
\text { bardziej efektywna. }\end{array}$ \\
\hline $\begin{array}{l}\text { Short- } \\
\text { Trerm } \\
\text { Subscore }\end{array}$ & 6,14 & 6,20 & 6,71 & $\begin{array}{l}\text { Wartość wskaźnika stale wzrasta, co } \\
\text { oznacza poprawę kondycji finansowej } \\
\text { przedsiębiorstwa. }\end{array}$ \\
\hline $\begin{array}{l}11 . \quad \text { Net } \\
\text { Surplus }\end{array}$ & 15624 & 23183 & 33242 & $\begin{array}{l}\text { Wzrost wskaźnika w kolejnych latach wiąże } \\
\text { się ze wzrostem wartości aktywów. }\end{array}$ \\
\hline $\begin{array}{l}12 . \\
\text { Contributio } \\
\text { n Ratio }\end{array}$ & 6,84 & 5,86 & 4,58 & 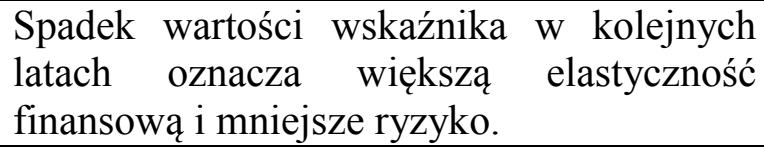 \\
\hline $\begin{array}{l}\text { 13. Self- } \\
\text { Financing } \\
\text { Ratio }\end{array}$ & 1,73 & 1,79 & 2,05 & $\begin{array}{l}\text { Wartość wskaźnika rośnie } \text { z każdym } \\
\text { rokiem. Wskaźnik powyżej } 1 \text { oznacza, że } \\
\text { można zwiększyć kapitał obrotowy. }\end{array}$ \\
\hline $\begin{array}{l}14 . \\
\text { Financial } \\
\text { Debt Ratio }\end{array}$ & 0,20 & 0,19 & 0,20 & $\begin{array}{l}\text { W przypadku danej organizacji spadek } \\
\text { wskaźnika wiąże się ze spadkiem } \\
\text { zobowiązań. Nieznaczny spadek wskaźnika } \\
\text { nastąpił w drugim roku. }\end{array}$ \\
\hline $\begin{array}{l}15 . \\
\text { Fundraising } \\
\text { Cost Ratio }\end{array}$ & 0,78 & 0,94 & 0,95 & $\begin{array}{l}\text { W każdym roku następuje wzrost wartości } \\
\text { wskaźnika. }\end{array}$ \\
\hline $\begin{array}{l}\text { Medium- } \\
\text { Term } \\
\text { Subscore }\end{array}$ & $-12,03$ & $-10,17$ & $-7,04$ & $\begin{array}{l}\text { Ujemne wartości wskaźnika pokazują } \\
\text { znaczny spadek tego składnika w ogólnej } \\
\text { kondycji finansowej. Jednakże sytuacja ta z } \\
\text { roku na rok się poprawia, co obrazuje } \\
\text { zwiększająca się wartość wskaźnika. }\end{array}$ \\
\hline$\Phi$ & 1,17 & 2,19 & 2,94 & Wartość wskaźnika rośnie $\mathrm{z}$ każdym \\
\hline
\end{tabular}




\begin{tabular}{|l|l|l|l|}
\hline & & $\begin{array}{l}\text { rokiem. Oznacza to wzrost kondycji } \\
\text { finansowej danego przedsiębiorstwa. }\end{array}$ \\
\hline
\end{tabular}

Źródło: Opracowanie własne na podstawie: J. Zietlow, A Financial Health Index for Achieving Nonprofit Financial Sustainability (2012). Dostęp SSRN: http://ssrn.com/abstract=2049022, ostatni dostęp: 29 listopada 2013.

Tabela 3: Analiza $\Phi$ dla organizacji non profit $\mathrm{Z}$

\begin{tabular}{|c|c|c|c|c|}
\hline Wskaźnik & 2008 & 2009 & 2010 & Interpretacja \\
\hline 1.Age & 2,56 & 2,64 & 2,71 & $\begin{array}{l}\text { Zwiększający się wskaźnik oznacza, że z } \\
\text { wiekiem jednostka jest bardziej stabilna } \\
\text { oraz zwiększają się jej zdolności } \\
\text { adaptacyjne, jest bardziej elastyczna. }\end{array}$ \\
\hline 2.Size & 16,60 & 16,84 & 16,75 & $\begin{array}{l}\text { Wzrost wskaźnika oznacza, że jednostka } \\
\text { jest bardziej stabilna i elastyczna, jednak w } \\
2010 \text { roku widać niewielki spadek. }\end{array}$ \\
\hline $\begin{array}{l}\text { 3.Asset } \\
\text { Instability } \\
\text { Index }\end{array}$ & $\begin{array}{l}1366474, \\
42\end{array}$ & $\begin{array}{l}1412558, \\
7\end{array}$ & $\begin{array}{l}1513251, \\
85\end{array}$ & $\begin{array}{l}\text { Na przestrzeni lat organizacja ma coraz } \\
\text { większe aktywa, jednak niestabilność } \\
\text { wzrostu aktywów wokół trendu utrudnia } \\
\text { proces zarządzania. }\end{array}$ \\
\hline $\begin{array}{l}\text { General } \\
\text { Subscore }\end{array}$ & 8,67 & 8,84 & 8,9 & $\begin{array}{l}\text { General Subscore z roku na rok rośnie, co } \\
\text { oznacza dobrą kondycję finansową, która z } \\
\text { roku na rok się polepsza. }\end{array}$ \\
\hline $\begin{array}{l}\text { 4.Cash } \\
\text { Reserve } \\
\text { Sufficiency } \\
\text { Ratio }\end{array}$ & 1,36 & 1,53 & 1,50 & $\begin{array}{lcccr}\text { Wskaźnik } & \text { utrzymuje } & \text { się } & \text { na } & \text { stabilnym } \\
\text { poziomie, powyżej } & 1 . & \text { Co } & \text { oznacza } \\
\text { możliwość } & \text { pokrywania } & & \text { wydatków } \\
\text { pieniężnych gotówką. } & & & \\
\end{array}$ \\
\hline $\begin{array}{l}\text { 5.Modified } \\
\text { Cash Ratio }\end{array}$ & $-0,24$ & 0,19 & 0,0092 & $\begin{array}{l}\text { W roku } 2009 \text { widać znaczny wzrost } \\
\text { wypłacalności z poziomu poniżej } 0 \text {, który } \\
\text { mógł świadczyć o kłopotach z } \\
\text { wypłacalnością, do poziomu } 0,19 \text {. Jednak w } \\
\text { kolejnym roku następuje spadek. }\end{array}$ \\
\hline $\begin{array}{l}\text { 6.Target } \\
\text { Liquidity } \\
\text { Lambda }\end{array}$ & 2,67 & 3,89 & 5,59 & $\begin{array}{l}\text { Stały wzrost wskaźnika } \text { zmniejsza } \\
\text { prawdopodobieństwo braku gotówki w } \\
\text { przyszłości. }\end{array}$ \\
\hline $\begin{array}{l}\text { 7.Current } \\
\text { Liquidity } \\
\text { Index }\end{array}$ & NA & NA & NA & $\begin{array}{l}\text { Organizacja nie posiada żadnych dłużnych } \\
\text { papierów wartościowych, obligacji itp. }\end{array}$ \\
\hline $\begin{array}{l}\text { Immediate- } \\
\text { Term } \\
\text { Subscore }\end{array}$ & 0,58 & 7,62 & 6,74 & 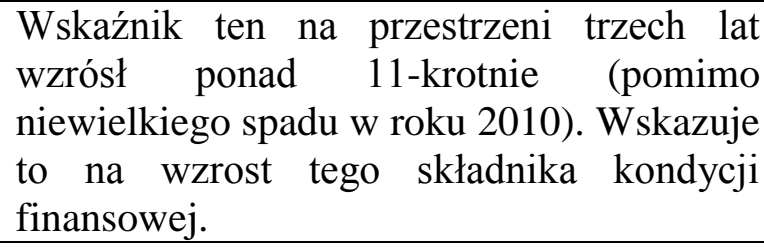 \\
\hline $\begin{array}{l}\text { 8.OCF } \\
\text { Ratio }\end{array}$ & 9,58 & 186,71 & $-1,76$ & $\begin{array}{l}\text { Zdolność pokrywania zobowiązań } \mathrm{z} \\
\text { operacyjnych przepływów pieniężnych } \\
\text { gwałtownie wzrosła ze względu na olbrzymi } \\
\text { spadek zobowiązań w } 2009 \text { roku. Po czym } \\
\text { spadła do wartości ujemnej w związku z }\end{array}$ \\
\hline
\end{tabular}




\begin{tabular}{|c|c|c|c|c|}
\hline & & & & $\begin{array}{l}\text { ujemnymi przepływami operacyjnymi } \mathrm{w} \\
\text { roku } 2010 .\end{array}$ \\
\hline $\begin{array}{l}\text { 9.Asset } \\
\text { Ratio }\end{array}$ & 0,95 & 0,95 & 0,77 & $\begin{array}{l}\text { W } 2010 \text { roku wartość wskaźnika spadła, co } \\
\text { oznacza spadek wypłacalności związany ze } \\
\text { spadkiem udziału aktywów obrotowych w } \\
\text { ogólnej liczbie aktywów. }\end{array}$ \\
\hline $\begin{array}{l}\text { 10.Adminis } \\
\text { trative } \\
\text { Expense } \\
\text { Ratio }\end{array}$ & 0,0095 & 0,011 & 0,011 & $\begin{array}{l}\text { Spadek wskaźnika mógłby przyczynić się } \\
\text { do wzrostu efektywności organizacji. } \\
\text { Sytuacja ta nie wystąpiła bowiem mamy do } \\
\text { czynienia z niewielkim wzrostem } \\
\text { wskaźnika. Jednak spadek zmniejsza } \\
\text { dodatkowo zdolność do pokrycia wydatków } \\
\text { administracyjnych w sytuacji kryzysowej. }\end{array}$ \\
\hline $\begin{array}{l}\text { Short-Term } \\
\text { Subscore }\end{array}$ & 13,54 & 146,43 & 3,86 & $\begin{array}{l}\text { Wskaźnik ten spadł ponad 4-krotnie na } \\
\text { przestrzeni trzech lat, co wskazuje na duży } \\
\text { spadek kondycji finansowej w tym } \\
\text { komponencie. }\end{array}$ \\
\hline $\begin{array}{l}\text { 11.Net } \\
\text { Surplus }\end{array}$ & $\begin{array}{l}199522,3 \\
6\end{array}$ & $\begin{array}{l}4452063, \\
31\end{array}$ & $\begin{array}{l}1994474, \\
18\end{array}$ & $\begin{array}{l}\text { Wzrost wskaźnika w } 2009 \text { roku związany } \\
\text { jest ze wzrostem wartości aktywów. Z kolei } \\
\text { spadek w } 2010 \text { roku wiąże się ze spadkiem } \\
\text { wartości aktywów. }\end{array}$ \\
\hline $\begin{array}{l}\text { 12.Contribu } \\
\text { tion Ratio }\end{array}$ & 43,04 & 2,93 & 7,54 & $\begin{array}{l}\text { Wysoki poziom wskaźnika w roku } 2008 \\
\text { wskazywał na wysokie ryzyko i małą } \\
\text { elastyczność. Dlatego spadek w roku } 2009 \\
\text { był pożądany. Niepokoić może kolejny } \\
\text { wzrost w } 2010 \text { roku. }\end{array}$ \\
\hline $\begin{array}{l}\text { 13.Self- } \\
\text { Financing } \\
\text { Ratio }\end{array}$ & 32,72 & 3,21 & 1,11 & $\begin{array}{l}\text { Zauważalny jest spadek samofinansowania } \\
\text { organizacji, mimo to, na przestrzeni lat cały } \\
\text { czas występuje nadwyżka (wskaźnik } \\
\text { powyżej 1), która jest przeznaczana na } \\
\text { kapitał obrotowy. }\end{array}$ \\
\hline $\begin{array}{l}\text { 14.Financia } \\
1 \\
\text { Ratio Debt }\end{array}$ & 0,06 & 0,001 & 0,04 & $\begin{array}{l}\text { Niska wartość wskaźnika oznacza, że } \\
\text { zadłużenie organizacji stanowi niewielką } \\
\text { cześć w finansowaniu jej działalności. }\end{array}$ \\
\hline $\begin{array}{l}\text { 15.Fundrais } \\
\text { ing Cost } \\
\text { Ratio }\end{array}$ & 1,84 & 1,22 & 1,11 & $\begin{array}{l}\text { Nie można orzec jaki poziom wskaźniki } \\
\text { byłby odpowiedni dla danej instytucji. } \\
\text { Wysoki wskaźnik powoduje niechęć } \\
\text { darczyńców do wspierania organizacji. } \\
\text { Dlatego nieznaczny spadek jest pożądany. }\end{array}$ \\
\hline $\begin{array}{l}\text { Medium- } \\
\text { Term } \\
\text { Subscore }\end{array}$ & $-22,44$ & 42,64 & 21,64 & $\begin{array}{l}\mathrm{Na} \text { przestrzeni lat wskaźnik ten bardzo } \\
\text { wzrósł, co oznacza wzrost tego komponentu } \\
\text { kondycji finansowej organizacji. }\end{array}$ \\
\hline$\Phi$ & 0,84 & 56,39 & 9,09 & $\begin{array}{l}\text { W roku } 2009 \text { widać znaczny wzrost } \\
\text { kondycji finansowej, która w kolejnym roku } \\
\text { znacznie spadła. }\end{array}$ \\
\hline
\end{tabular}

Źródło: Opracowanie własne na podstawie: J. Zietlow, A Financial Health Index for Achieving Nonprofit Financial Sustainability (2012). Dostęp SSRN: http://ssrn.com/abstract=2049022, ostatni dostęp: 29 listopada 2013. 


\section{Bibliografia}

1. Borowiecki Ryszard, Jaki Andrzej (red.), Wspótczesne problemy analizy ekonomicznej, Wyd. Katedra Ekonomiki i Organizacji Przedsiębiorstw Uniwersytetu Ekonomicznego w Krakowie, Kraków 2010, s. 26.

2. Epstein Marc J., Warren McFarlan Franklin, Joining a Nonprofit Board. What you need to know, Wyd. Jossey-Bass A Wiley Imprint, San Francisco 2011, s. 1.

3. Fudaliński Janusz, Perspektywy rozwoju zarzadzania społecznego $w$ sektorze organizacji non profit w Polsce, Wyd. Difin, Warszawa 2013, s. 21.

4. Gołaś Zbigniew, Witczyk Anna, Pojęcie $i$ metody oceny plynności finansowej przedsiębiorstwa, Journal of Agribusiness and Rural Development, Nr 1(15), 2010, s. 92.

5. Grant Julia, Munter Paul, Robinson Thomas R., Financial statement analysis: a global perspective, Pearson Education International, New Jersey 2004, s. 239.

6. Jemielniak Dariusz, Latusek Dominika, Zarzadzanie: teoria i praktyka od podstaw. Ćwiczenia, Wyd. Wyższa Szkoła Przedsiębiorczości i Zarządzania im. Leona Koźmińskiego, Warszawa 2005, s. 11.

7. Korol Tomasz, Nowe podejście do analizy wskaźnikowej $w$ przedsiębiorstwie, Wyd. Wolters Kluwer Polska, Warszawa 2013, s. 24.

8. Leszczyński Zdzisław, Skowronek-Mielczarek Anna, Analiza działalności i rozwoju przedsiębiorstwa, Polskie Wydawnictwo Ekonomiczne, Warszawa 2008, s. 17.

9. Leszczyńki Zdzisław, Skowronek-Mielczarek Anna, Analiza ekonomiczno-finansowa firmy, Wyd. Difin, Warszawa 2001, s. 20.

10. Lichtarski Janusz Marek, Moroz Mirosław, Osbert-Pociecha Grażyna, Elastyczność przedsiębiorstwa jako konfiguracja elastyczności cząstkowych, Gospodarka Narodowa, Nr 4, 2008, s. 59. 
11. Maness Terry S., Zietlow John, Short-term Financial Management, Wyd. Thomson South-Western, Mason 2005, s. 40.

12. Ofiarski Zbigniew, Prawo bankowe, Wyd. Wolters Kluwer Polska, Warszawa 2011, s. 17.

13. Okolski Józef (red.), Prawo handlowe, Wyd. Wolters Kluwer Polska, Warszawa 2008, s. 270.

14. Wędzki Dariusz, Analiza wskaźnikowa sprawozdania finansowego, Wyd. Wolters Kluwer Polska, Kraków 2006, s. 323.

15. Zietlow John, A Financial Health Index for Achieving Nonprofit Financial Sustainability, Dostęp SSRN: http://ssrn.com/abstract=2049022, ostatni dostęp 02.12.2013. 